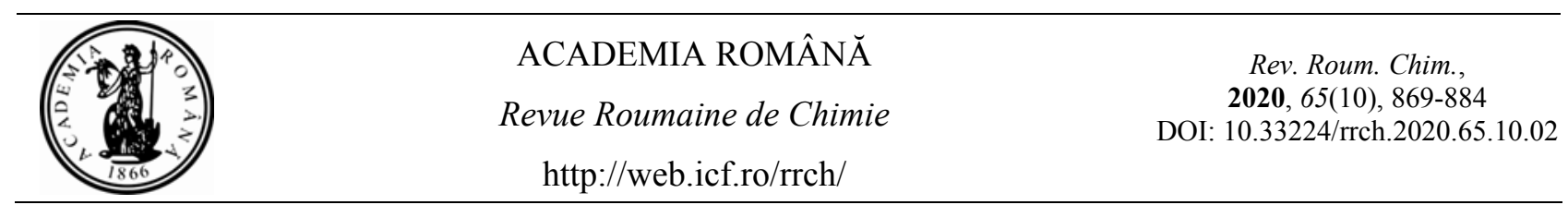

\title{
ADSORPTION PERFORMANCE OF ANIONIC TEXTILE DYE (NYLOSAN RED N-2RBL) ONTO RAW, SODIC AND FRACTIONATED SODIC INORGANIC CLAY MATERIAL
}

\author{
Smail TERCHI, ${ }^{\mathrm{a},{ }^{*}}$ Naziha LADJAL, ${ }^{\mathrm{a}}$ Belkacem ZIDELKHEIR ${ }^{\mathrm{a}}$ and Khaldoun BACHARI ${ }^{\mathrm{b}}$ \\ ${ }^{a}$ Department of Chemistry, Faculty of Science, University Mohamed BOUDIAf -M'Sila, Bp 166, 28000 M'sila, Algeria \\ ${ }^{\mathrm{b}}$ Center for Scientific and Technical Research in Physico-Chemical Analysis (CRAPC), BP 248, 16004 Bou Ismaïl, Algeria
}

The inorganic montmorillonitic clay material in raw and modified forms (sodic and fractionated sodic materials) was evaluated as adsorbent for anionic textile dye (Nylosan Red N2RBL). A various characterization using XRD, XRF, AFM, FTIR, TG, adsorption of methylene blue and $\mathrm{pH}_{\mathrm{PCN}}$ of the considered samples was realized. The experimental results show that, the adsorption was $\mathrm{pH}$ dependent with a high adsorption capacity of NR dye in acidic range. The pseudo-second-order kinetic model provided the best fit to the experimental data for the adsorption of dye by clay materials. The equilibrium adsorption data were analyzed by Langmuir, Freundlich and Dubinin-Radushkevich isotherm models. The best fit of experimental data was obtained by the Dubinin-Radushkevich isotherm model. The maximum adsorption capacity of the raw clay calculated by the latest isotherm model is $62.05 \mathrm{mg} / \mathrm{g}$. It is increased in modified forms (170.11 and $201 \mathrm{mg} / \mathrm{g}$ for sodic clay and fractionated sodified clay materials, respectively). Increasing solution ionic strength $\left(\mathrm{NaCl}, \mathrm{KCl}, \mathrm{NaNO}_{3}\right.$, and $\mathrm{Na}_{2} \mathrm{SO}_{4}$ ) increased significantly the adsorption of dye.

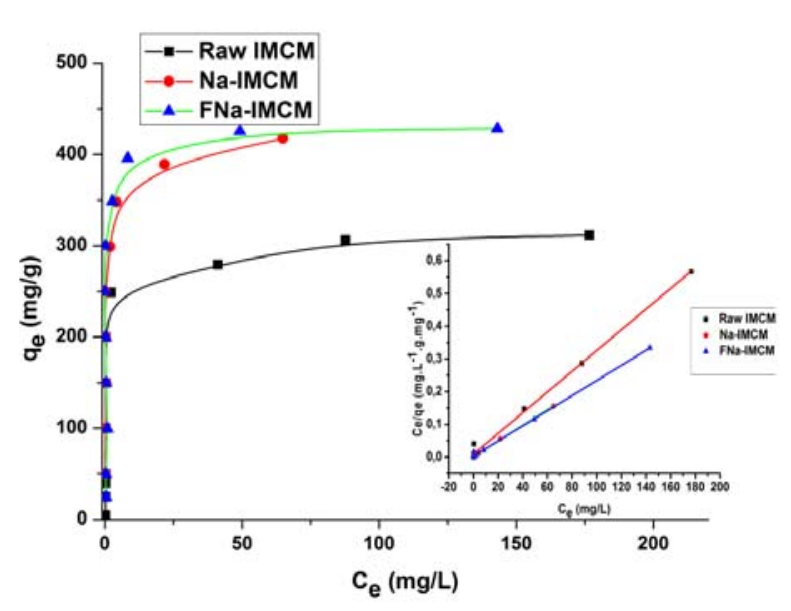

\section{INTRODUCTION}

The presence of dyes in textile effluents can pose a serious environmental threat when they are discharged into biosphere without prior treatment or with an inadequate level of treatment. ${ }^{1,2}$ Various physical, chemical, and biological methods, including ozonation/ oxidation, ${ }^{3}$ coagulation/ flocculation, ${ }^{4,5}$ photocatalytic degradation, 6 sonochemical degradation, electrochemical degradation, membrane separation, ${ }^{7,8}$ and biological process ${ }^{9}$ have been used for the treatment of dyes containing wastewaters.

But most of these conventional methods are beginning to prove insufficient for simple and effective treatment, in addition they are also very expensive. ${ }^{10}$ Adsorption is a very effective separation technique and it is now considered to be the best wastewater treatment technique in terms of initial cost, simplicity of design and ease of use. ${ }^{11,12}$

Many adsorbents have been tested to reduce dye concentrations in aqueous solutions. Activated

\footnotetext{
*Corresponding author: terchismail@gmail.com, smail.terchi@univ-msila.dz
} 
carbon is considered as an effective technique for the treatment of polluted water by organic and inorganic materials, because the activated carbon has a high adsorption capacity due to its large surface area. 13,14 But it is an expensive adsorbent due to its high costs of manufacturing and regeneration. ${ }^{15}$

Therefore, many studies in recent years have focused on the use of various low-cost adsorbents to replace activated carbon such as some adsorbents including agricultural wastes, ${ }^{16}$ natural phosphate, ${ }^{17}$ some natural biosorbents, ${ }^{18,} 19$ hybrid materials, ${ }^{20-23}$ and clay materials ${ }^{24-26}$ have also been reported. Using inorganic clays materials as alternative adsorbents in wastewater treatments would provide several advantages due to their lowcost, abundant availability, non-toxicity and high potential of ion exchange for charged pollutants. Clay materials have a high adsorption capacity due to their lamellar structure which provides high specific surface areas. ${ }^{27}$

There are many types of clay materials but montmorillonite is expected to have the highest sorptive capacity in comparison to other. ${ }^{28}$ Its adsorption capacity for cations and organic molecules is high because of their colloidal properties and negatively charged layers. ${ }^{29}$ However, its adsorption capacity is small for anions in natural states, but this can be improved using surfactants (usually alkylammonium cations) that modify the surface charge of the clay from negative to positive or under acidic conditions when complexation occurs because of the amphoteric character of the crystal edges..$^{30-32}$ But before the organophilization process, the raw material should be modified by sodic cations, because $\mathrm{Na}^{+}$ions can be easily exchanged by surfactants cations, and fractionated in order to eliminate the host impurities. Acid Nylosan Red N$2 \mathrm{RBL}$ is one of the anionic dyes that are used in textile filed. Elimination of this dye from aqueous solution was studied by electrocoagulation, ${ }^{33,34}$ and adsorption methods; using activated carbon, ${ }^{35}$ and biosorbents. ${ }^{19}$ The inorganic clay materials as adsorbents have never been studied in the literature.

The focus of the present study was to assess the potentiality of the Algerian Inorganic montmorillonite clay material as a low-cost adsorbent for the removal of this dye from aqueous solution. This procedure is considered as an ideal alternative to the current expensive methods of removing textile dyes from wastewater. The raw clay material (raw IMCM) was sodified and fractionated (particules size is $<2 \mu \mathrm{m}$ ) in order to improve its adsorption capacity. Adsorption studies were carried out under various parameters such as $\mathrm{pH}$, contact time, initial dye concentration, dose of adsorbent and salinity. The adsorption kinetic data was tested by pseudo-first-order, pseudo- second-order and intraparticle diffusion kinetic models. The equilibrium data were analyzed using Langmuir, Freundlich and Dubinin-Radushkevich isotherm models.

\section{EXPERIMENTAL}

\section{Materials and Methods}

\subsection{Materials}

All the necessary chemicals used in the study were of analytical grade. Methylene blue (MB) and sodium chloride $(\mathrm{NaCl})$ were provided by the Biochem Chemipharma. The anionic dye Nylosan Red N-2RBL was provided from Varian.

\subsection{Purification and Modification of the Raw Material}

The original inorganic clay material used was Maghnia montmorillonite. It was isolated from Maghnia clay (Algeria) by successive decantation from the aqueous suspensions.

The raw material was dried in the oven at $110^{\circ} \mathrm{C}$ for four days, ground in an agate mortar and sieved in $90 \mu \mathrm{m}$ filter. The obtained powder was immersed in a $(30 \%) \mathrm{H}_{2} \mathrm{O}_{2}$ solution for $48 \mathrm{~h}$ in order to eliminate the organic material. The clay suspension was then washed seven times in distilled water at $30{ }^{\circ} \mathrm{C}$ using the centrifugation process. Dried at $50{ }^{\circ} \mathrm{C}$ for five days, the precipitate was sieved in $100 \mu \mathrm{m}$ filters (this sample denoted as raw IMCM). Raw IMCM was added into $\mathrm{NaCl}$ solution with a mass ratio of Clay/ $\mathrm{NaCl}=100 / 5.55$ and stirred for $8 \mathrm{~h}$ at $70^{\circ} \mathrm{C}$. The suspension was washed several times with distilled water using the centrifugation method until no chloride ion was detected with silver nitrate $\left(\mathrm{AgNO}_{3}\right)$ solution $(0.1 \mathrm{~N})$ test. The precipitate was then dried at $80^{\circ} \mathrm{C}$ for $24 \mathrm{~h}$ in the vacuum oven. The product was ground and sieved through $90 \mu \mathrm{m}$ for further use. The treated sodium montmorillonite is designed as (Na-IMCM). The (Na-IMCM) suspension was placed into centrifuge tubes, and then the suspension was siphoned off by suction using a syringe in order to recover the montmorillonite fraction whose particle size is $<2 \mu \mathrm{m}$. For each sampling, the procedure was repeated many times to collect an adequate amount of fractionated montmorillonite. The recovered suspension was then dried at $80^{\circ} \mathrm{C}$ and crushed with a mortar. The fractionated montmorillonite was designed as FNa- IMCM. ${ }^{36}$

\subsection{Characterization}

The samples obtained were characterized by a variety of conventional techniques.

Elemental analysis was performed to get information about the main elements in the samples. X-ray fluorescence (XRF) S4 Explorer from Bruker, was used for this purpose.

The XRD analyses were performed in a Bragg-Brentano geometry using a Brukers D8 Advance diffractometer (acceleration voltage of $40 \mathrm{kV}$ and an electron current of $30 \mathrm{~mA}$ ) equipped with a Ge monochromator and using the $\mathrm{Cu}$ $\mathrm{K}_{\alpha 1}$ incident radiation $(\lambda=1.5406 \AA)$.

The samples were combined with $\mathrm{KBr}$ and compacted under 7 tons into a disc for analysis with a FTIR spectrometer (Thermo Electron Corporation-Nicolet 380 FTIR spectrometer). The infrared spectra were carried out between 400 and $4000 \mathrm{~cm}^{-1}$ with a resolution of $2 \mathrm{~cm}^{-1}$ with 64 scans.

Thermal gravimetric (TG) analysis was performed using DW5470H63 STA analyser under a flowing nitrogen atmosphere, and heated from room ambient temperature to $700{ }^{\circ} \mathrm{C}$, with a heating rate of $10^{\circ} \mathrm{C} / \mathrm{min}$. 
The atomic force microscopy (AFM) images of the samples were obtained with an Asylum Research (Oxford Instruments) type: MFP-3D. It is used for the surface morphologies.

The $\mathrm{pH}$ of suspension of the material $(0.15 \mathrm{~g})$ and $\mathrm{NaCl}$ aqueous solution $\left(50 \mathrm{~mL}\right.$ at $0.01 \mathrm{~mol} . \mathrm{L}^{-1}$ ) was adjusted to successive initial values between 2 and 12 . The suspensions were stirred $48 \mathrm{~h}$ at $20^{\circ} \mathrm{C}$ and the final $\mathrm{pH}$ was measured and plotted versus the initial $\mathrm{pH}$. The $\mathrm{pH}_{\mathrm{PZC}}$ is determined at the value for which $\mathrm{pH}_{\text {final }}=\mathrm{pH}_{\text {initial }}$

In this study, Methylene blue is used for the determination of specific surface area (SSA) and cationic exchange capacity (CEC) of the inorganic clay materials. Methylene blue dye has been used for determining SSA and CEC for various inorganic clay materials for several studies. ${ }^{37,}{ }^{38}$ Methylene blue in aqueous state is a cationic dye, $\mathrm{C}_{16} \mathrm{H}_{18} \mathrm{~N}_{3} \mathrm{~S}^{+}$, which can be adsorbed onto negatively charged clay surfaces. The MB molecule has a rectangular shape with dimensions $17 \AA \times 7.6 \AA \times 3.25 \AA$, and it is assumed that MB molecule lies on its largest surface. The surface area covered by one $\mathrm{MB}$ molecule is assumed to be about $17 \AA \times 7.6 \AA \approx 130 \AA^{2}$. Santamarina et al. ${ }^{39}$ compared $\mathrm{MB}$ and $\mathrm{N}_{2}$ (BET) adsorption methods for surface area determination. They remarked that $\mathrm{N}_{2}$ adsorption method gives low values of SSA in swelling clays because $\mathrm{N}_{2}$ cations cannot insert into interlayers space. The $\mathrm{N}_{2}$ adsorption method yields only external surface; however, MB method can yield both external and internal surface area of clays.

Methylene blue (Sigma-Aldrich, dye content $\geq 82 \%$ ) adsorption was studied onto inorganic clay materials. Adsorption studies were carried out with $100 \mathrm{mg}$ of clay introduced into $50 \mathrm{~mL}$ of $\mathrm{MB}$ solutions with different initial concentrations in the range $10-1000 \mathrm{mg} . \mathrm{L}^{-1}$. The $\mathrm{pH}$ of the suspensions was adjusted at $\mathrm{pH}=6$, using nitric acid $\left(1 \mathrm{~mol} . \mathrm{L}^{-1}\right)$ or sodium hydroxide $\left(1 \mathrm{~mol} . \mathrm{L}^{-1}\right)$ solutions. The adsorption equilibrium of $\mathrm{MB}$ on materials was reached after $18 \mathrm{~h}$ of stirring at $20{ }^{\circ} \mathrm{C}$ and $300 \mathrm{rpm}$. After filtration, the MB equilibrium concentrations were determined by spectrophotometry at $665 \mathrm{~nm}$ (Shimadzu UV-2101PC). After calibration line which having high regression coefficient value; 0.999, the $\mathrm{MB}$ equilibrium concentrations were calculated by this relation:

$$
C_{e}=(A b s-0.0029) / 0.2
$$

The amount of MB adsorbed $\left(\mathrm{q}_{\mathrm{e}}\right)$ was calculated from the difference between the initial and equilibrium $\mathrm{MB}$ concentrations;

$$
q_{e}=\left(C_{i}-C_{e}\right) \cdot V / m
$$

where $\mathrm{q}_{\mathrm{e}}$ is the amount of BM adsorbed per unit mass of clay $(\mathrm{mg} / \mathrm{g}), C_{i}$ and $C_{e}$ are the initial and equilibrium $\mathrm{MB}$ concentrations $(\mathrm{mg} / \mathrm{L}), m$ is the mass of used clay $(0.1 \mathrm{~g})$ and $V$ is the volume of solution $(50 \mathrm{~mL})$.

Adsorption isotherms of MB were fitted by the langmuir model using the linearized Langmuir equation:

$$
C_{e} / q_{e}=1 /\left(k_{L} q_{m}\right)+C_{e} / q_{m}
$$

where $k_{L}$ is the Langmuir constant and $q_{m}(\mathrm{mg} / \mathrm{g})$ is the maximum amount of dye which can be adsorbed. The maximum amount of adsorbed MB allows estimating the specific surface area of clay covered by the MB molecules from the equation:

$$
\operatorname{SSA}\left(\AA^{2} / g\right)=q_{m} \times A_{m} \times 6.02 \times 10^{23} / M_{M B}
$$

with a molecular surface of $\mathrm{MB}\left(A_{m}\right)$ of $130 \AA^{2}$ and the 284 g.mol ${ }^{-1}$ molecular mass of $\mathrm{MB}\left(\mathrm{M}_{\mathrm{MB}}\right){ }^{40}$

Generally, the maximum amount of $\mathrm{MB}$ adsorbed corresponds to $1 C E C$ of clay. For example, an MB adsorption capacity of $0.9 \mathrm{mmol} / \mathrm{g}$, corresponding to 1,06 of its $C E C$, was found on SWy-1 montmorillonite. ${ }^{41} C E C$ for each sample was calculated from the equation written according to the definition:

$$
\text { CEC }(\mathrm{mmol} / \mathrm{g})=q_{m} / M_{M B}
$$

\subsection{Adsorption of Nylosan Red Experiments}

The adsorption of the anionic dye Nylosan Red N-2RBL onto inorganic clay materials was also studied in batch adsorption experiments. The main properties and chemical structure of NR are reported in Table 1. The effects of time (adsorption kinetics), $\mathrm{pH}$ of solution, concentration (equilibrium experiments), adsorbent (material) dose and ionic strength have been investigated.

The kinetic study was carried out at $20{ }^{\circ} \mathrm{C}$. Several solutions of RN of $50 \mathrm{~mL}$ and initial concentration of $100 \mathrm{mg} \cdot \mathrm{L}^{-1}$ were prepared. They were mixed with $100 \mathrm{mg}$ of material in stoppered agitated flasks (300 rpm). The residual dye concentration in each flask was determined after increasing contact time (between $2.5 \mathrm{~min}$ and $360 \mathrm{~min}$ ).

Table 1

Properties of Nylosan Red N-2RBL. ${ }^{35}$

\begin{tabular}{l|l}
\hline Chemical name & $\begin{array}{l}\text { Sodium 6-amino-5-[[4-chloro-3-[[(2,4- dimethylphenyl) amino] } \\
\text { sulfonyl]phenyl]azo]-4-hydroxynaphthalene-2-sulfonate } \\
71873-39-7\end{array}$ \\
$\begin{array}{l}\text { C.A.S. number } \\
\text { Color index: C.I. }\end{array}$ & Acid $\mathrm{Red} 336$ \\
Chemical formula & $\mathrm{C}_{24} \mathrm{H}_{21} \mathrm{ClN}_{4} \mathrm{O}_{6} \mathrm{~S}_{2}, \mathrm{Na}$ \\
Molecular weight $\left(\mathrm{g} . \mathrm{mol}^{-1}\right)$ & 587.97 \\
$\begin{array}{l}\text { Molecular size }\left(\AA^{3}\right) \\
\lambda_{\max }(\mathrm{nm}) \\
\text { Chemical structure }\end{array}$ & $14.7 \times 13.1 \times 6.6$ \\
& 500
\end{tabular}


Batch $\mathrm{pH}$ studies were conducted by shaking $50 \mathrm{~mL}$ of each dye solution with $0.1 \mathrm{~g}$ of the clay for $18 \mathrm{~h}$, a range of $\mathrm{pH}$ values from 2 to 12 . The $\mathrm{pH}$ of the solutions was adjusted with $\mathrm{HCl}$ or $\mathrm{NaOH}$ solution by using a $\mathrm{pH}$ meter. The flasks were homogenized by agitation with a magnetic stirrer $(300 \mathrm{rpm})$ at $20^{\circ} \mathrm{C}$.

The equilibrium adsorption experiments were carried out in stoppered flasks containing $0.1 \mathrm{~g}$ of clay and $50 \mathrm{~mL}$ of Nylosan Red solution of initial concentration in the 5-400 $\mathrm{mg} \cdot \mathrm{L}^{-1}$ range for $18 \mathrm{~h}$ at $\mathrm{pH}=4$ and $20^{\circ} \mathrm{C}$.

In order to determine the adsorbent-adsorbate equilibrium of the system, it is necessary to study the effect of adsorbent dose. The dependence of the adsorption of NR on the adsorbent dosage was studied by varying the amount of raw material (raw IMCM) within the range $1-4 \mathrm{~g} / \mathrm{L}$ maintaining all other parameters constant $\left(\mathrm{pH}=4, C_{i}=100 \mathrm{mg} / \mathrm{L}, t=18 \mathrm{~h} V=50\right.$ $\mathrm{mL}$ and $T=20^{\circ} \mathrm{C}$ ).

The effect of ionic strength on the adsorption uptake of the raw material was investigated using different salts $(\mathrm{NaCl}, \mathrm{KCl}$, $\mathrm{NaNO}_{3}$, and $\mathrm{Na}_{2} \mathrm{SO}_{4}$ ) solutions from 0.01 to $1 \mathrm{~mol} / \mathrm{L}$ and an initial dye concentration of $100 \mathrm{mg} / \mathrm{l}$ at $\mathrm{pH} 4,2 \mathrm{~g} / \mathrm{L}$ adsorbent dose, $t=18 \mathrm{~h}$ and $T=20^{\circ} \mathrm{C}$.

After filtration, the NR equilibrium concentrations were determined by spectrophotometry at $502 \mathrm{~nm}$ (Shimadzu UV2101PC). After calibration line which having high regression coefficient value; 0.993 , the $\mathrm{RN}$ equilibrium concentrations were calculated by this relation:

$$
C_{e}=(A b s-0,0283) / 0,0107
$$

The amount of NR adsorbed $\left(q_{e}\right)$ was also calculated from the difference between the initial and equilibrium NR concentrations:

$$
q_{e}=\left(C_{i}-C_{e}\right) \cdot V / m
$$

where $q_{e}$ is the amount of NR dye adsorbed per unit mass of clay $(\mathrm{mg} / \mathrm{g}), C_{i}$ and $C_{e}$ are the initial and equilibrium NR concentrations $(\mathrm{mg} / \mathrm{L}), \mathrm{m}$ is the mass of used material and $V$ is the volume of solution $(50 \mathrm{ml})$. The percentage removal (adsorption efficiency) of the dyes (NR and $\mathrm{MB}$ ) was calculated by following relation:

$$
R(\%)=\left[\left(C_{i}-C_{e}\right) / C_{i}\right] \times 100
$$

\section{RESULTS AND DISCUSSION}

\section{Characterization of the Inorganic Clay Materials}

Elemental analysis was performed to get information about the main elements in the inorganic clay material. The chemical composition ( $\%$ of mass) of raw IMCM and Na- IMCM samples are respectively: (Mg: 2.76, $\mathrm{Al}: 18.3, \mathrm{Si}$ : 59.7, P: 0.17, K: 8.65, Ca: 3.19, Ti: 0.67, Mn: 0.11, Fe: 6.11, Rb: 0.16 and traces of $\mathrm{Zn}, \mathrm{As}, \mathrm{Sr}, \mathrm{Zr}, \mathrm{Nb}$ :
0.13), (Mg: 3.46, Al: 19.9, Si: 58, K: 5.82, Ca: 3, Na: 2.11, Ti: 0.41, Fe: 6.64, and traces of Rb, Mn, $\mathrm{P}, \mathrm{Zn}, \mathrm{As}, \mathrm{Sr}, \mathrm{Zr}, \mathrm{Nb}: 0.44)$.

The raw material is mainly composed of $(\mathrm{Si})$ and $(\mathrm{Al})$. It contains also $(\mathrm{Fe})$ and $(\mathrm{Mg})$ and exchangeables cations $\mathrm{Ca}^{+2}, \mathrm{~K}^{+}$. For Na-IMCM sample, a decrease of $\mathrm{K}^{+}$and $\mathrm{Ca}^{2+}$ cations is observed, this decreasing is substituted by $\mathrm{Na}^{+}$ cations with a cationic exchange process.

Figure 1 reveals the X-ray spectra for raw IMCM, Na-IMCM and FNa-IMCM. Bragg's equation was used to calculate the basal spacing of the samples. For raw IMCM, the peaks at $2 \theta$ equal to $5.94^{\circ}\left(\mathrm{d}_{001}=15.24 \AA\right.$, interlayer spacing $)$, $20^{\circ}\left(\mathrm{d}_{110}=4.5 \AA\right)$ and $35^{\circ} \quad\left(\mathrm{d}_{110}=2.5 \quad \AA\right)$, corresponding to the reflections hkl, (001), (110) and (200), respectively, are characteristics of the pure montmorillonite. Some peaks related to impurities like quartz (Q) at $2 \theta=26.7^{\circ}$ and cristobalite $(C)$ at $2 \theta=20.8^{\circ}$ are observed. For the Na-MMT sample, the interlayer spacing $\left(\mathrm{d}_{001}=12.5\right.$ $\AA)$ is smaller than that of raw MMT (15.24 $\AA$ ), confirming the intercalation of $\mathrm{Na}^{+}$cations into IMCM interlayer space. For the fractionated sample (FNa- IMCM), the disappearance of some peaks related to impurities like quartz $(\mathrm{Q})$ and cristobalite (C) is observed. ${ }^{42}$

FTIR spectra of raw IMCM, Na-IMCM and FNa-IMCM are shown in Figure 2. For raw IMCM sample, bands at $1025 \mathrm{~cm}^{-1}$ is attributed to stretching vibration of $\mathrm{Si}-\mathrm{O}-\mathrm{Si}$ from silicate, 915 $\mathrm{cm}^{-1}$ (from Al-OH-Al deformation of aluminates), 800 , and $460 \mathrm{~cm}^{-1}$ are attributed to $\mathrm{Si}-\mathrm{O}-\mathrm{Al}$ stretching and $\mathrm{Si}-\mathrm{O}$ bending vibrations of the montmorillonite material, respectively were observed. ${ }^{43}$ Antisymmetric stretching vibrations of structural -OH groups in IMCM sheets at $3625 \mathrm{~cm}^{-1}$, symmetric stretching vibrations from water molecule observed at $3416 \mathrm{~cm}^{-1}$, and in-plane bending vibrations of $\mathrm{H}-\mathrm{O}-\mathrm{H}$ at $1636 \mathrm{~cm}^{-1}$ are very sensitive and respond to changes in the structure of the montmorillonite material were also observed. ${ }^{44}$ For Na-IMCM and FNa-IMCM, the intensity of $-\mathrm{OH}$ bands ( $-\mathrm{OH}$ of water) was increased to a large extent due to the intercalation of $\mathrm{Na}^{+}$cations, leading to the formation of more hydrophile surface. 


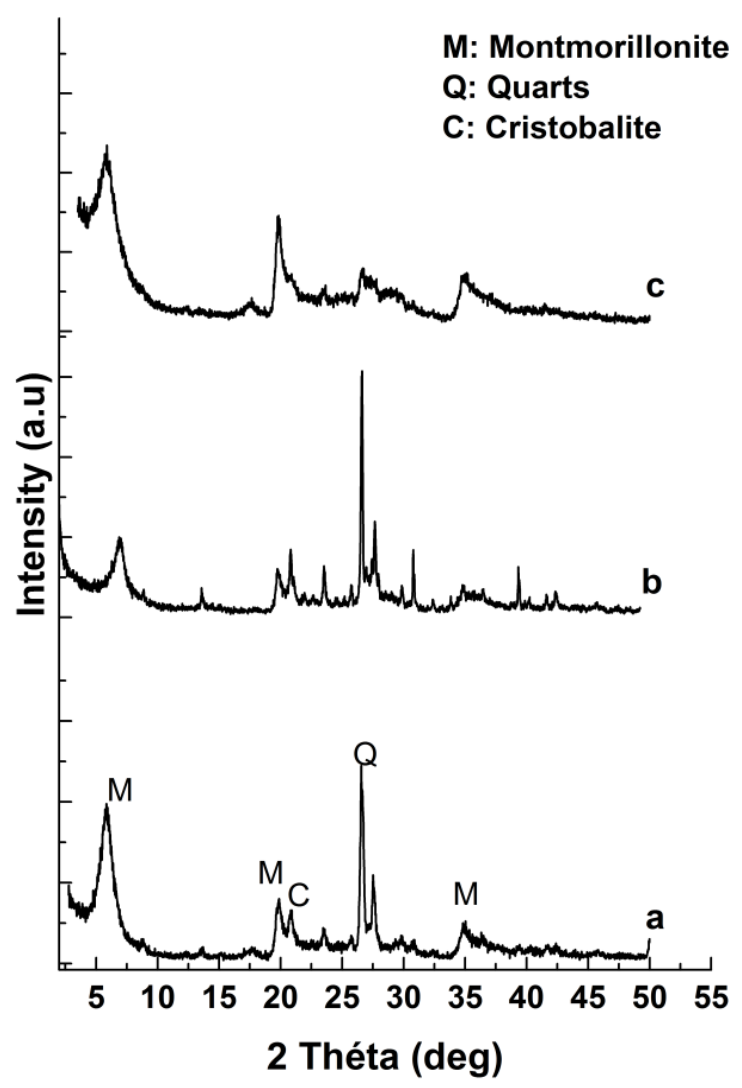

Fig. 1 - XRD patterns of raw IMCM a), Na-IMCM b) and FNa-IMCM c).

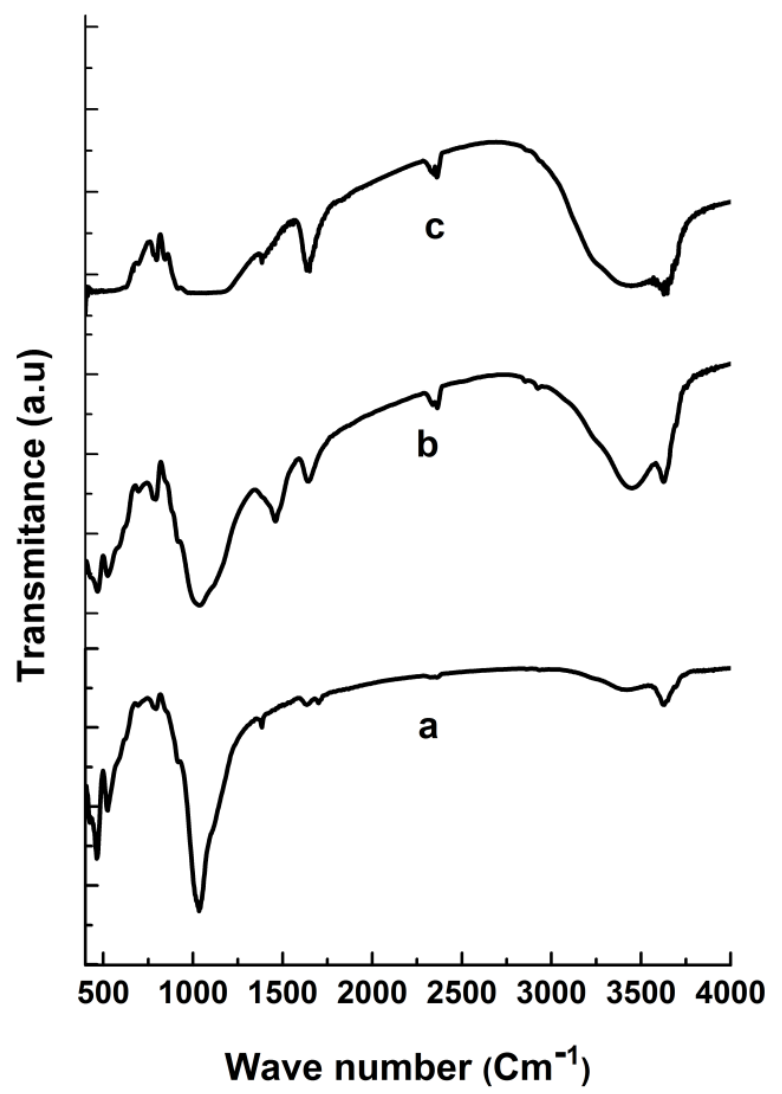

Fig. 2 - Infrared spectra of Raw IMCM a), Na-IMCM b) and FNa-IMCM c). 

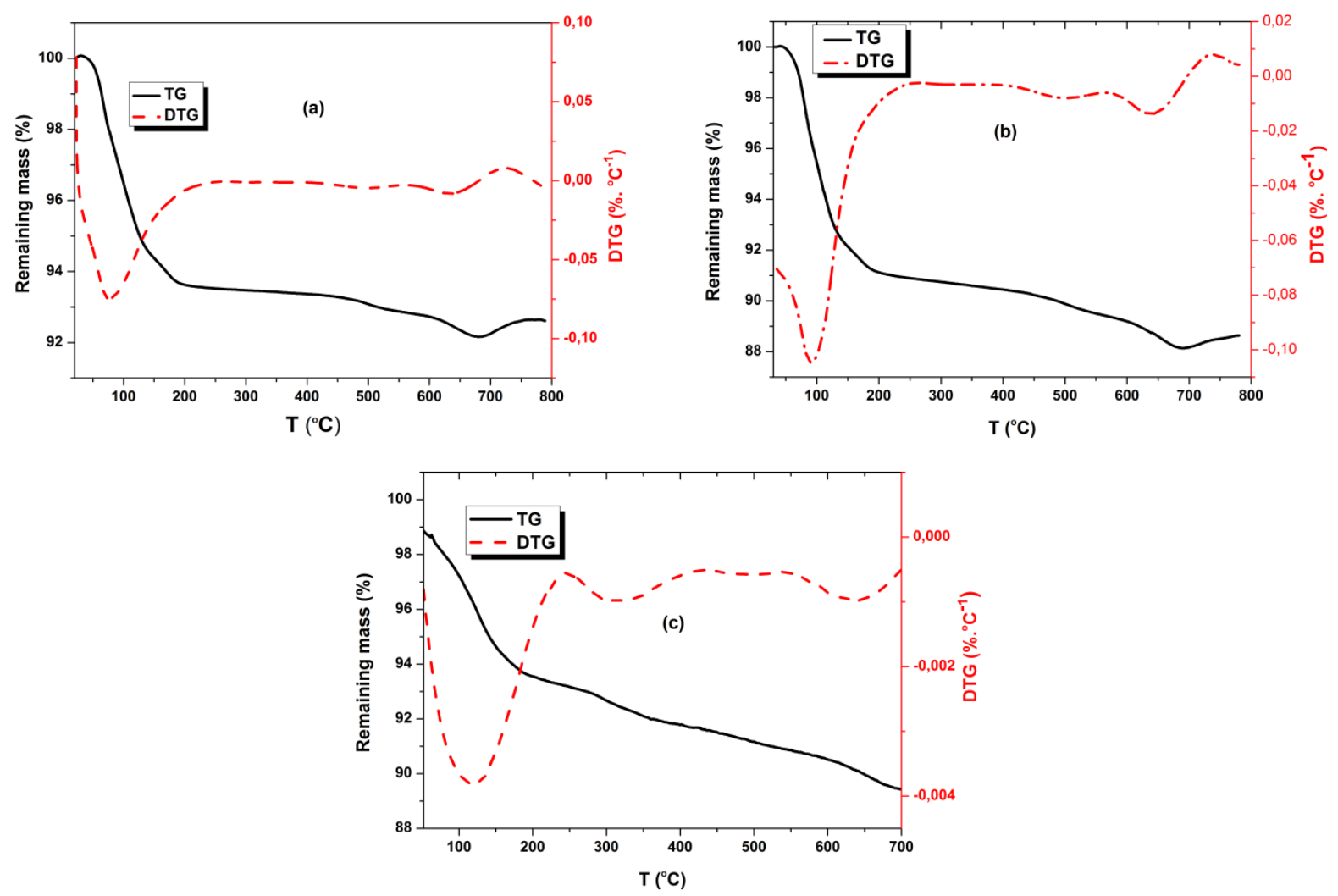

Fig. 3 - TG and DTG curves of raw IMCM a), Na-IMCM b) and FNa-IMCM $\left({ }^{36}\right.$ c).

Both thermogravimetric (TG) and its derivative (DTG) curves, in inert atmosphere, of raw IMCM (Fig. 3a) reveals two degradation steps with maxima at $75{ }^{\circ} \mathrm{C}$ and $656{ }^{\circ} \mathrm{C}$ related to the following mass losses: first $(6,1 \%)$ observed in the temperature range from 40 to $135{ }^{\circ} \mathrm{C}$ and second (1\%) between 624 and $755{ }^{\circ} \mathrm{C}$. These mass loss steps were attributed to desorption of adsorbed water from the particle surfaces and dehydration of the hydrated cations in the interlayer space $\left(\mathrm{Ca}^{+2}\right.$ and $\left.\mathrm{K}^{+}\right),{ }^{45},{ }^{46}$ and loss of $\mathrm{OH}$ units through dehydroxylation of the montmorillonite. ${ }^{47}$ However, the mass loss of adsorbed and interlayer water is increased in the case of Na-IMCM sample $(9.2 \%)$ in comparaison with raw IMCM (6.1\%) in the same temperature range (Fig. 3b) This is due to the fact that $\mathrm{Na}^{+}$cations is more hydrated in comparison with $\mathrm{Ca}^{+2}$ and $\mathrm{K}^{+}$cations. The fractionated sample (FNa-IMCM) reveals a decrease in mass loss $(7.25 \%)$ relatively to $\mathrm{Na}$ IMCM sample (Fig. 3c). This can be explained by the disappearance of some $\mathrm{Na}^{+}$cations during the fractionation process. The mass loss of dehydroxylated $\mathrm{OH}$ units in the temperature range $\left(624-755^{\circ} \mathrm{C}\right)$ remains unchanged for all samples.

Figure 4 displays the 3D AFM images $(10 \mu \mathrm{m}$ $\times 10 \mu \mathrm{m}$ ) of the samples thin pellets (Raw IMCM, Na-IMCM and FNa-IMCM). The measured root- mean-square (RMS) roughness of the raw IMCM sample was $194.79 \mathrm{~nm}$, and it is the less smooth sample. For the sodic clay sample (Na-IMCM), the value of RMS was decreased to $123.988 \mathrm{~nm}$. The surface protrusions were less pronounced for $\mathrm{Na}$ IMCM than raw IMCM. This surface modification can be interpreted by the high hydropholic state of sodic clay than raw clay, which leads to a smooth structure. For the fractionated sodic clay sample (FNa-IMCM $<2 \mu \mathrm{m}$ ), the value of RMS was more decreased to $52.724 \mathrm{~nm}$. The surface protrusions were less pronounced for FNa-IMCM than NaIMCM. This surface modification can be interpreted by the small particles size of $\mathrm{FNa}$ IMCM $(<2 \mu \mathrm{m})$ than Na-IMCM, which leads to a more smooth structure.

The $\mathrm{pH}_{\mathrm{f}}=f\left(\mathrm{pH}_{\mathrm{i}}\right)$ curves and $\mathrm{pH}_{\mathrm{PZC}}$ values of all samples are reported in Figure 5 and Table 2 respectively. It was noticed that after treatment of raw clay material with $\mathrm{NaCl}$ solution; the $\mathrm{pH}_{\mathrm{PZC}}$ value is unchanged. This result can be explained by the neutral $\mathrm{pH}$ of $\mathrm{NaCl}$ solution that can not affect the surface charge of the raw clay. However, in previous study when the adsorbent material was treated with basic or acidic solutions the $\mathrm{pH}_{\mathrm{PZC}}$ were shifted respectively to high or low values compared to untreated adsorbent. ${ }^{48}$ 

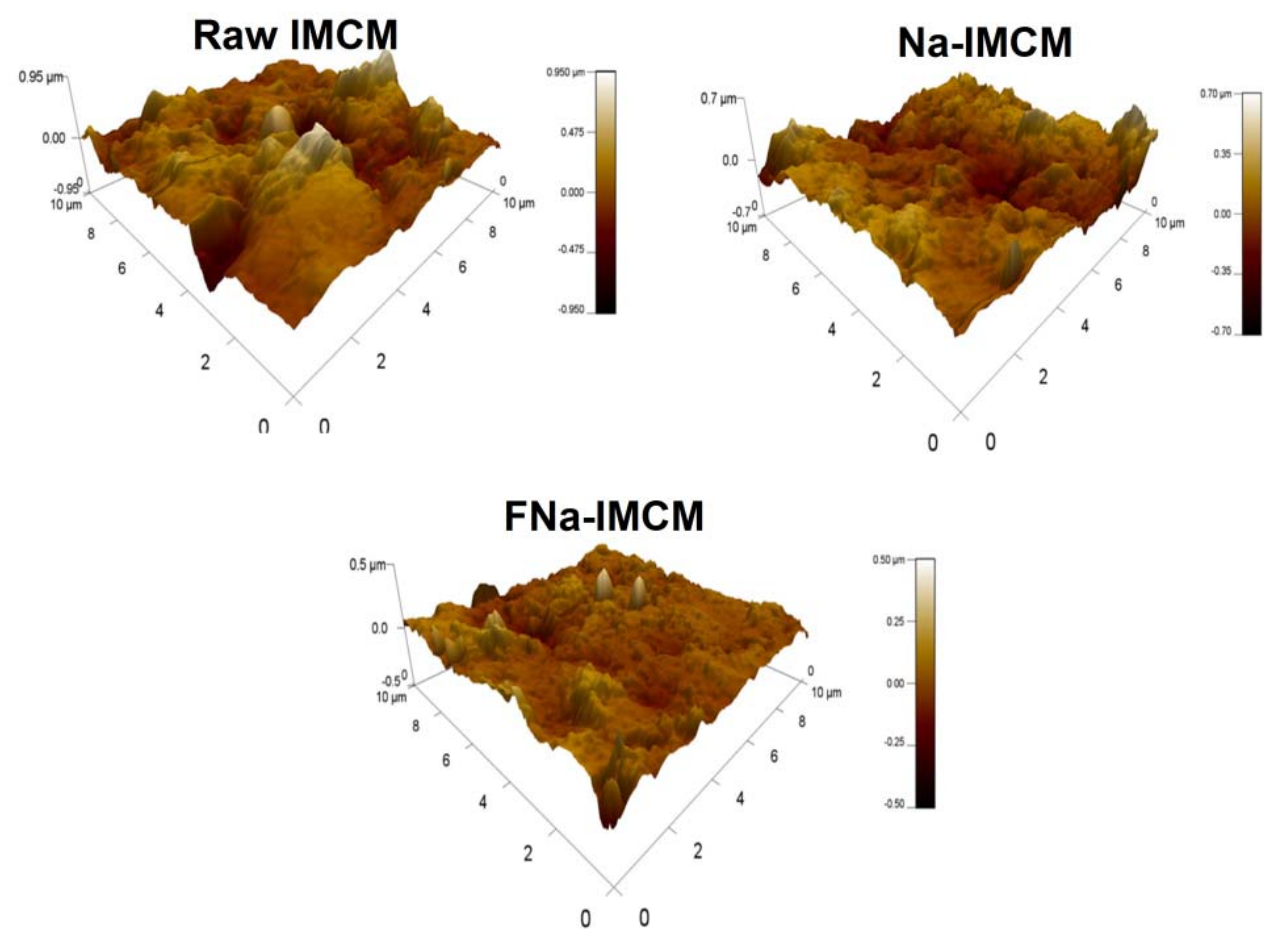

Fig. 4 - AFM images of raw IMCM (a), Na-IMCM (b) and FNa-IMCM $\left({ }^{36} \mathrm{c}\right)$.

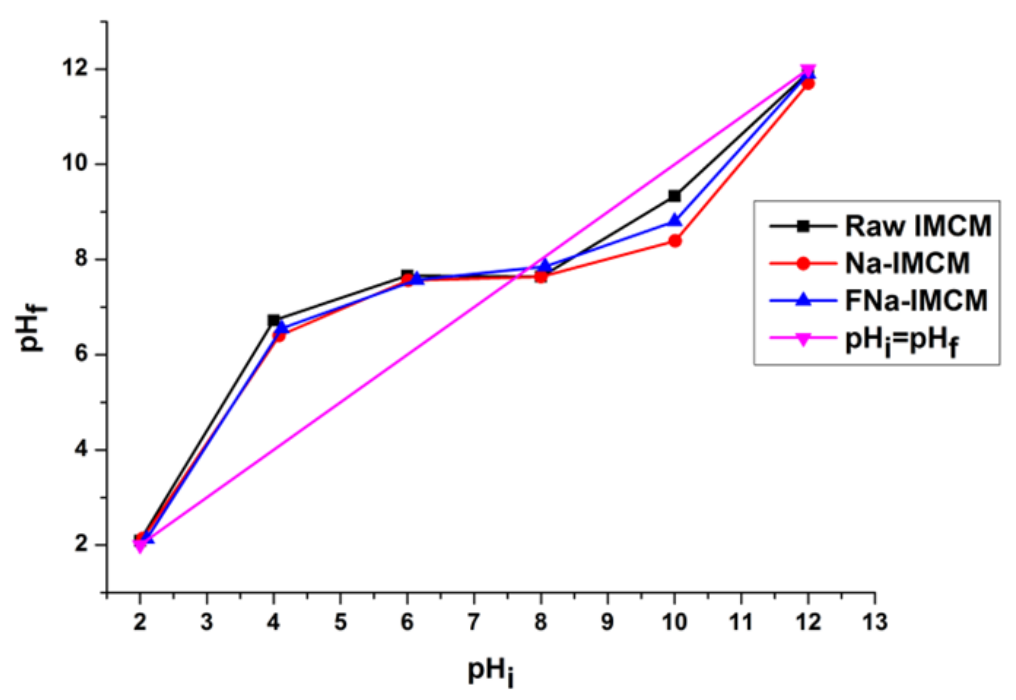

Fig. 5 - Evolution of the $\mathrm{pH}_{\mathrm{f}}$ according to the $\mathrm{pH}_{\mathrm{i}}$ of the samples.

After fractionation process, the $\mathrm{pH}_{\mathrm{PZC}}$ value is slightly increased from 7.58 for Na-ICM to 7.77 for FNa-ICM. This result may be due to the disappearance of acidic or less basic impurities during the fractionation process.

The values of SSA and CEC of samples were reported in the Table 2.

The SSA and CEC values of raw IMCM were increased when converted to Na-IMCM, because the sodium IMCM when added in aqueuse solution; absorb water many times as its dry mass present in water and expand when it is wetted, it is very significant because of its important colloidal properties. ${ }^{49}$ These properties lead to an increase in surface of contact with adsorbate and lead to an increase in $S S A$ and $C E C$. However, a slight increase in $S S A$ and $C E C$ is observed from NaIMCM to FNa-IMCM structure because the impurities are eliminated. 
Table 2

SSA, CEC and $\mathrm{pH}_{\mathrm{PZC}}$ of inorganic clay materials

\begin{tabular}{l|l|l|l}
\hline & \multicolumn{1}{|c|}{$S S A\left(\mathrm{~m}^{2} / \mathrm{g}\right)$} & \multicolumn{1}{c}{$C E C(\mathrm{mmol} / \mathrm{g})$} & \multicolumn{1}{c}{$\mathrm{pH}_{\mathrm{PZC}}$} \\
\hline Raw MMT & 869.26 & 1.11 & 7.60 \\
Na-MMT & 1157.80 & 1.47 & 7.58 \\
FNa-MMT & 1192.91 & 1.52 & 7.77 \\
\hline
\end{tabular}

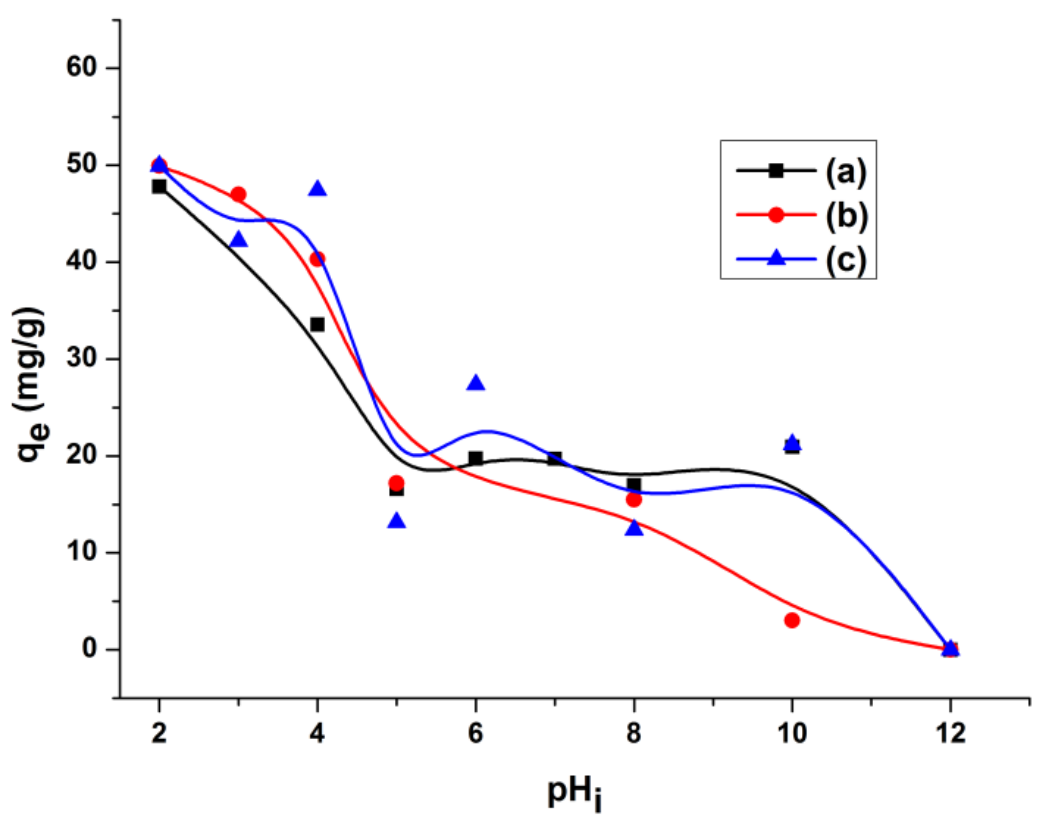

Fig. 6 - Effect of pH on adsorption of RN by raw IMCM a), Na-IMCM b) and FNa-IMCM c).

\section{Dye Adsorption Results}

\subsection{Effect of $\mathrm{pH}$}

Solution $\mathrm{pH}$ is an important factor in the adsorption process, which not only influences the surface charge of adsorbent but also physicochemical properties of adsorbate. ${ }^{50}$ The points of zero charge $\left(\mathrm{pH}_{\mathrm{pzc}}\right)$ of the materials were about 7.6-7.8.

When $\mathrm{pH}<\mathrm{pH}_{\mathrm{pzc}}$ the materials are charged positively ( $\mathrm{S}-\mathrm{OH}+\mathrm{H}^{+}=\mathrm{S}-\mathrm{OH}_{2}{ }^{+}$).

However, when $\mathrm{pH}>\mathrm{pH}_{\mathrm{pzc}}$ they are charged negatively $\left(\mathrm{S}-\mathrm{OH}+\mathrm{OH}^{-}=\mathrm{S}_{-} \mathrm{O}^{-}+\mathrm{H}_{2} \mathrm{O}\right)$.

Effect of $\mathrm{pH}$ on adsorption of Nylosan Red dye onto materials curves are showed in Figure 6.

The adsorption is high in acidic range (highest at $\mathrm{pH}=2$ ) and decreases with the increase in $\mathrm{pH}$ of the medium for all materials. Adsorption of NR dye onto materials resulted from electrostatic interactions between the adsorbents and the NR molecules. At low $\mathrm{pH}$, the positively charged surface sites on the materials favor the adsorption of the anionic dye due to the electrostatic attraction. But at higher $\mathrm{pH}$, the negatively charged surface sites on the adsorbents does not favor the adsorption of the anionic dye due to the electrostatic repulsion and excess $\mathrm{OH}^{-}$competing with the dye anions for the adsorption sites. ${ }^{51,52}$

\subsection{Effect of Contact Time and Kinetic Study}

Contact time aids in finding the optimum time at which equilibrium of adsorption is reached. Most studies show that adsorption of dyes onto clay materials occurs rapidly at the first few minutes of contact and then proceeds gradually until equilibrium is reached. ${ }^{53}$

The removal of NR dye onto materials (raw IMCM, Na-IMCM and FNa-IMCM) was rapid in the short initial contact time (less than $15 \mathrm{~min}$ ) and gradually decreased with time until equilibrium (Fig. 7-a). The rapid adsorption observed during the first few minutes is probably due to the abundant availability of active sites on the clays surface, and with the gradual occupancy of these sites, the sorption becomes less efficient. It appears from Fig. 7-a that the contact time needed to reach equilibrium conditions was 30 to $60 \mathrm{~min}$.

Adsorption rate constants for the NR were calculated by using three kinetics models (pseudofirst order, pseudo-second order and intraparticle diffusion equations) in order to fit experimental results. 
Lagergren pseudo-first order equation: ${ }^{56}$

$$
\ln \left(q_{e}-q_{t}\right)=\ln q_{e}-k_{l} t
$$

where $q_{e}$ and $q_{t}$ are the amounts of dye adsorbed per unit weight of adsorbent $(\mathrm{mg} / \mathrm{g})$ at equilibrium time and time $\mathrm{t}$, respectively, and $k_{l}$ is the rate constant for the first order kinetics. The adsorption rate constant $\left(k_{l}\right)$ was determined from plotting of $\ln \left(q_{e}-q_{t}\right) v$ s. $t$.

Pseudo-second-order equation

The pseudo-second-order kinetics equation: ${ }^{57}$

$$
t / q_{t}=1 / k_{2} q_{e}^{2}+t / q_{e}
$$

where $k_{2}$ is the rate constant for second order kinetics, $q_{e}$ and $q_{t}$ are the amount of dye adsorbed at equilibrium time $(\mathrm{mg} / \mathrm{g})$ and time $t(\mathrm{mg} / \mathrm{g})$, respectively. The values of $q_{e}$ and $k_{2}$ $\left(\mathrm{mg} \cdot \mathrm{g}^{-1} \cdot \mathrm{min}^{-1}\right)$ can be determined experimentally from the slope and intercept of plot of $t / q_{t}$ vs. $t$. The initial adsorption rate is

$$
h=k_{2} q_{e}^{2}
$$

Intraparticle diffusion equation: ${ }^{59}$

If the diffusion of dye molecules on internal surfaces of pores and capillaries of the adsorbent is the rate-limiting step, the adsorption data can be presented by the following equation:

$$
q_{t}=K_{d} \cdot t^{0.5}+C
$$

where $k_{d}$ represents intraparticle diffusion rate constant $\left(\mathrm{mg} . \mathrm{g}^{-1} \cdot \mathrm{min}^{-0.5}\right)$ and $C$ is a constant $(\mathrm{mg} / \mathrm{g}) \quad$ which gives information about the thickness of boundary layer. The plot of $q_{t}$ versus $t^{0.5}$ yields a straight line passing through the origin in case of intraparticle diffusion.
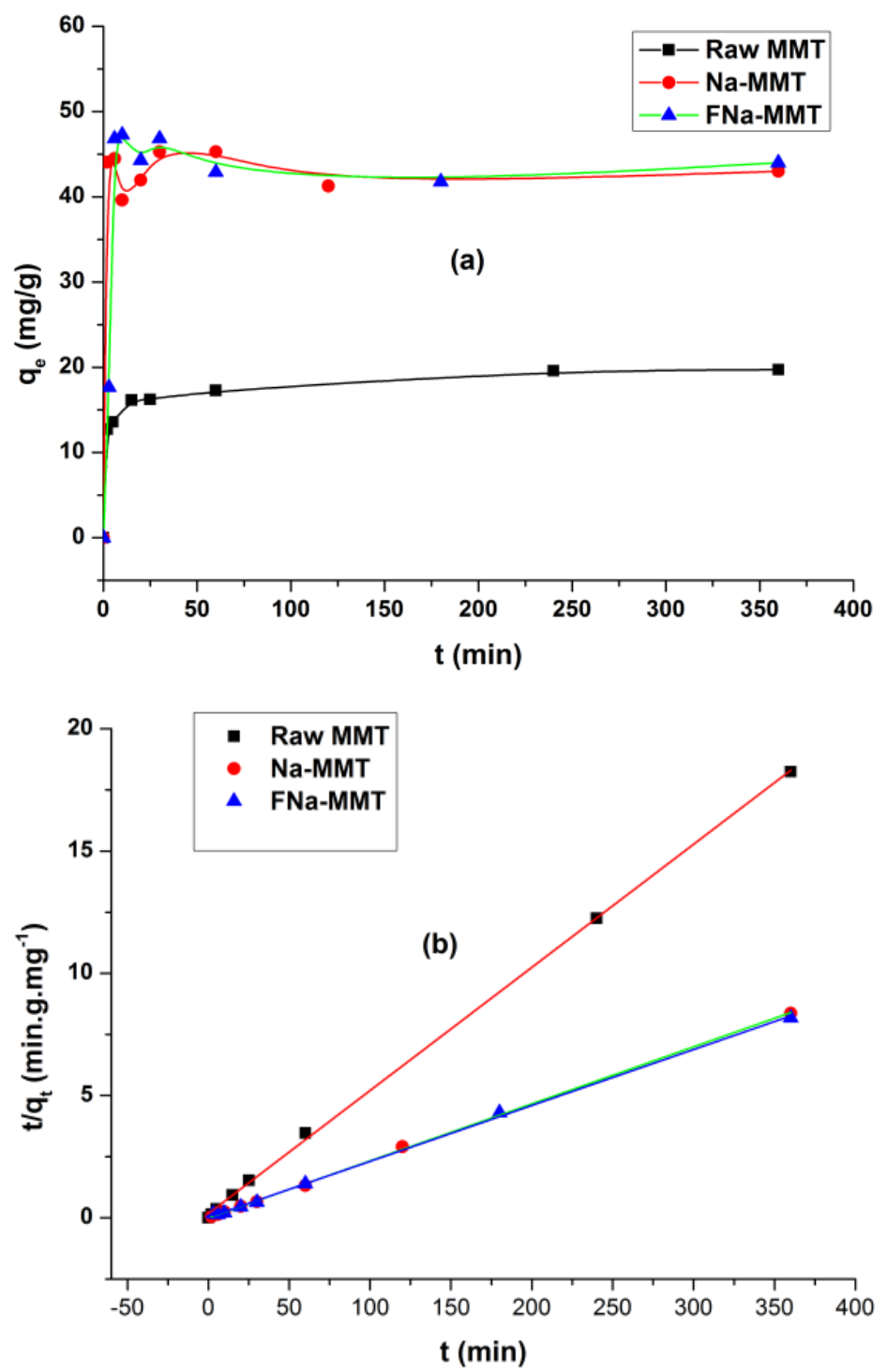

Fig. 7 - Adsorption kinetic of Nylosan Red onto inorganic clay materials (a), and pseudo second-order kinetics modeling (b). 
Table 3

Kinetic constants for NR dye adsorption onto inorganic clay materials

\begin{tabular}{|c|c|c|c|c|c|c|c|c|c|c|c|}
\hline & \multicolumn{4}{|c|}{ Pseudo first-order } & \multicolumn{4}{|c|}{ Pseudo second-order } & \multicolumn{3}{|c|}{ Intraparticle diffusion model } \\
\hline & $\begin{array}{l}q_{\text {e(exp) }} \\
(\mathrm{mg} / \mathrm{g})\end{array}$ & $\begin{array}{l}q_{e(\text { The })} \\
(\mathrm{mg} / \mathrm{g})\end{array}$ & $\begin{array}{l}\mathrm{k}_{1} \\
\left(\min ^{1}\right)\end{array}$ & $\mathrm{R}^{2}$ & $\begin{array}{l}q_{e(\text { The })} \\
(\mathrm{mg} / \mathrm{g})\end{array}$ & $\begin{array}{c}\mathrm{K}_{2} \\
(\mathrm{~g} / \mathrm{mg} \\
\mathrm{min})\end{array}$ & $\begin{array}{c}h \\
\mathrm{mg} / \mathrm{g} \cdot \min \end{array}$ & $\mathrm{R}^{2}$ & $\begin{array}{c}\mathrm{K}_{\mathrm{d}} \\
(\mathrm{mg} . \\
\left./ \mathrm{g}^{\circ} \min ^{0.5}\right)\end{array}$ & $\begin{array}{c}\mathrm{C} \\
(\mathrm{mg} / \mathrm{g})\end{array}$ & $\mathrm{R}^{2}$ \\
\hline RawMMT & 19.72 & 7.51 & 0.017 & 0.893 & 19.91 & 0.0121 & 5.85 & 0.999 & 0.366 & 13.601 & 0.835 \\
\hline Na-MMT & 45.28 & 13.79 & 0.0055 & 0.272 & 44.30 & 17.570 & 34482 & 0.999 & 0.023 & 43.27 & 0.161 \\
\hline FNaMMT & 47 & 25.50 & 0.011 & 0.355 & 45.70 & 0.020 & 42.19 & 0.999 & 0.37 & 38.78 & 0.103 \\
\hline
\end{tabular}

The low value of $R^{2}$ (Table 3 ) and the difference between $q_{\text {exp }}$ (experimental adsorption capacity) and $q_{\text {the }}$ (theoretical adsorption capacity) indicate that the Pseudo-first-order model was not well suited for describing the adsorption of NR used in this study. The low value of $R^{2}$ for intraparticle diffusion plot indicates that this model was also not only rate controlling step. High $R^{2}$ values $\left(R^{2}=0.999\right)$ indicate that Pseudo-second order model successfully describes the kinetics dye adsorption by all inorganic clay materials (Fig. 7b).

\subsection{Effect of Initial Dye Concentration and Adsorption Isotherms}

It is possible to depict the equilibrium adsorption isotherm graphically by plotting a solid phase against a liquid phase concentrations. Among many theories relating to adsorption equilibrium and in order to describe the interactions between the $\mathrm{RN}$ and clays, single component adsorption isotherms equations have been tested in the present research, namely Langmuir, Freundlich and Dubinin-Radushkevich. These isotherms ${ }^{60-62}$ are represented by the following linearized equations:

The Langmuir isotherm which assumes that the adsorption takes place at specific homogeneous sites within the adsorbent is given by the following equation:

$$
C_{e} / q_{e}=1 / k q_{m}+\left(1 / q_{m}\right) C_{e}
$$

where $q_{e}$ is amount of dye adsorbed per unit weight of adsorbent $(\mathrm{mg} / \mathrm{g}) . C_{e}$ is the concentration of dye remaining in solution at equilibrium $(\mathrm{mg} / \mathrm{L}) . q_{m}$ $(\mathrm{mg} / \mathrm{g})$ is the maximum adsorption capacity corresponding to complete monolayer coverage and $k$ is a constant related to the energy or net enthalpy.

The Freundlich isotherm used to describe adsorption tests taking place on heterogeneous adsorbent surface is given by the following equation:

$$
\log q_{e}=\log k_{f}+(1 / n) \log C_{e}
$$

where $K_{f}$ and $n$ are the Freundlich constants related to adsorption capacity and adsorption intensity that can be obtained from the intercept and slope of $\log$ $q_{e}$ vs. $\log C_{e}$ plot.

The Dubinin-Radushkevich isotherm model does not assumes a homogenous surface or constant sorption potential as other models. It can be noted that the (D-R) isotherm is more general that the Langmuir fit. The $\mathrm{D}-\mathrm{R}$ isotherm has been written by the following equations

$$
\begin{gathered}
\ln q_{e}=\ln q_{m}-B \varepsilon^{2} \\
\varepsilon=R T \ln \left(1+1 / C_{e}\right)
\end{gathered}
$$

where $B$ is a constant related to the adsorption energy ( $\mathrm{mol} / \mathrm{J})$ and $q_{m}$ is the theoretical adsorption capacity $(\mathrm{mg} / \mathrm{g}), \varepsilon$ is the Polanyi potential, that can be obtained respectively ( $B$ and $q_{m}$ ) from the slope and intercept of $\ln q_{e}$ vs. $\varepsilon^{2}$.

Adsorption capacity increases with concentration for all considered clays (Fig. 8-a), showing that the considered clays (raw IMCM, NaIMCM and FNa-IMCM) are able to retain high quantities of dye and can be used when highly polluted waters should be treated.

In order to know the adsorption mechanism of NR (anionic dye) onto clays, the adsorption capacity $\left(q_{e}\right)$ and adsorption efficiency $(R(\%))$ of MB (cationic dye) at the equilibrium onto raw MMT versus initial MB concentration was plotted (Fig. 9-a). It was found strong adsorption efficiency $(99 \%)$ at low $\mathrm{MB}$ concentrations. It was unchanged when $\mathrm{MB}$ concentration was in the range of $10-500 \mathrm{mg} / \mathrm{L}$. In this range the adsorption capacity $\left(q_{e}\right)$ increased with increasing initial dye concentration. However, this efficiency decreased by increasing in initial dye concentration beyond $500 \mathrm{mg} / \mathrm{L}$ and the adsorption capacity $\left(q_{e}\right)$ was unchanged. This fact could be explained by the saturation of adsorption sites at the surface of clay. ${ }^{63,64}$ 

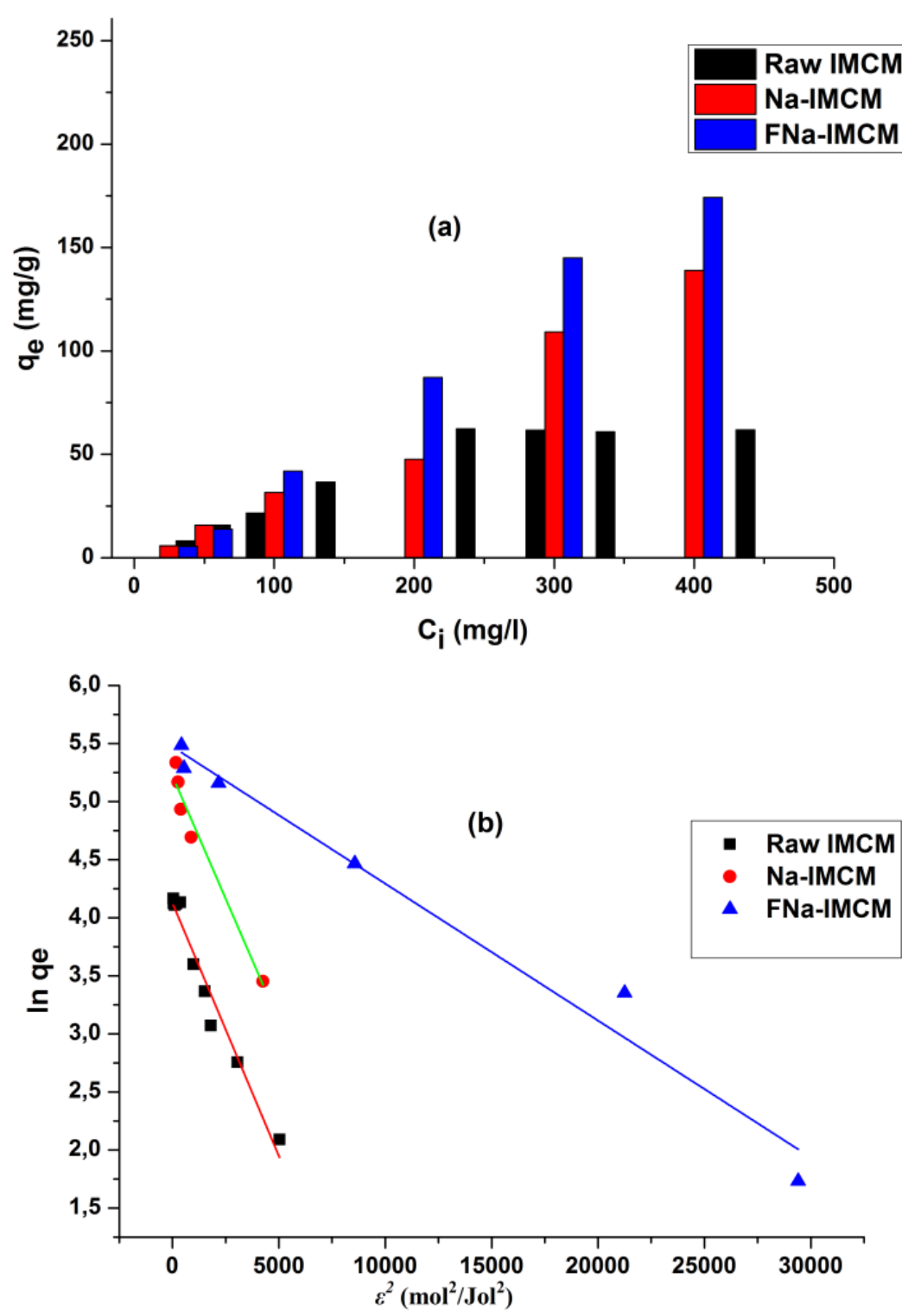

Fig. 8 - NR dye initial concentration influence over the adsorption capacity on inorganic clay materials (a) and D-R isotherms modeling (b).
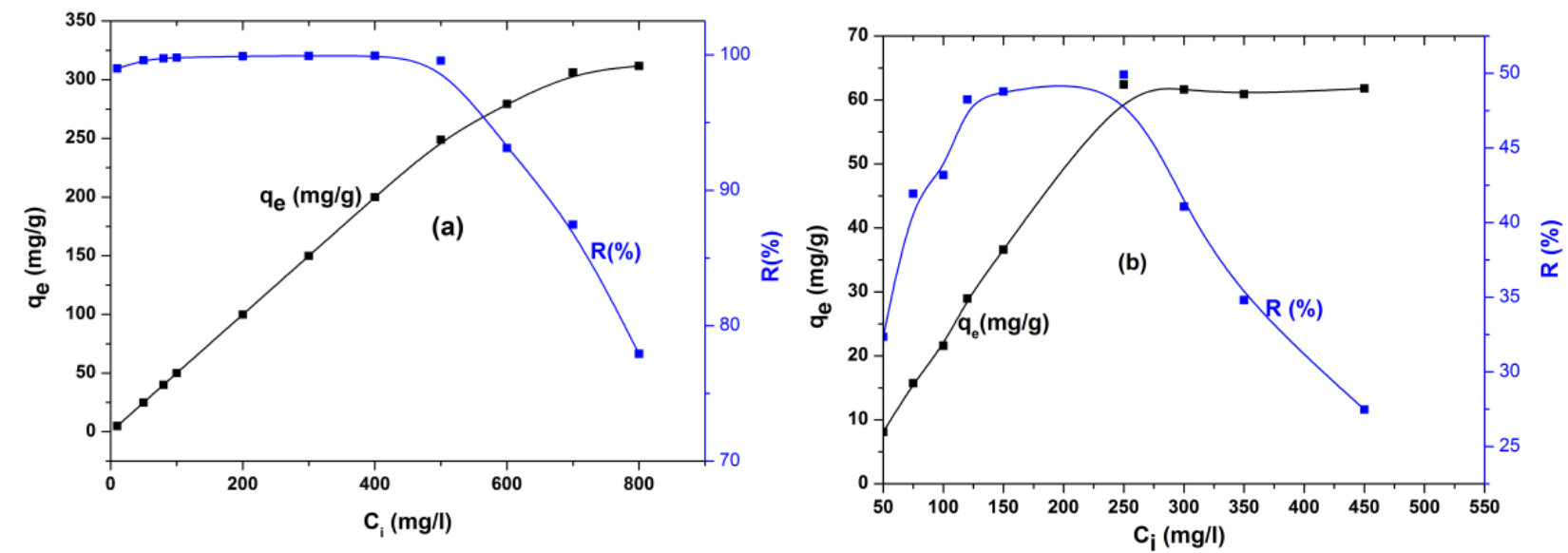

Fig. 9 - Effect of initial dyes concentration (MB: (a), NR: (b)) on the adsorption onto raw material and the percentage dye removal. 


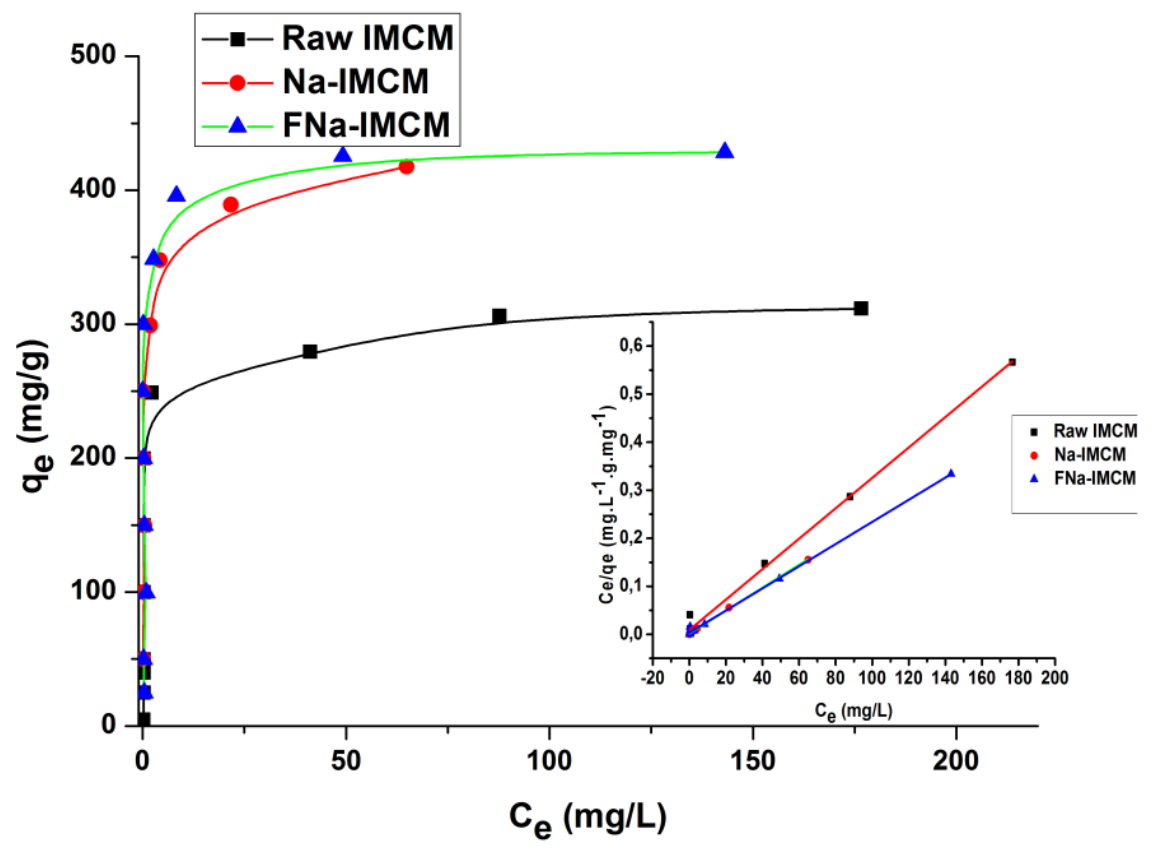

Fig. 10 - Equilibrium isotherms for adsorption of MB onto inorganic clay materials.

The adsorption isotherms of MB dye (Fig. 10) are of the type H. ${ }^{65}$ Generally, Isotherms types $\mathrm{H}$ are the result of the dominance of strong adsorbate-adsorbent interactions. ${ }^{66}$

A chemical adsorption of positively charged functional groups of $\mathrm{MB}$ on the negatively charged surface groups of the clay material is proposed. The best fit of experimental data in the case of MB was obtained with the Langmuir model (Table 4).

This result suggests that the adsorption process of MB (cationic dye) by the inorganic clay material was monolayer adsorption and the maximum monolayer adsorption capacities were found to be $315.45 \mathrm{mg} / \mathrm{g}(1.1 \mathrm{mmol} / \mathrm{g})$ for Raw IMCM. For modified forms; $420.16 \mathrm{mg} / \mathrm{g}(1.47 \mathrm{mmol} / \mathrm{g})$ for $\mathrm{Na}-\mathrm{IMCM}$ and $432.90 \mathrm{mg} / \mathrm{g}(1.52 \mathrm{mmol} / \mathrm{g})$ for FNa- IMCM.

However, in the case of the anionic textile dye (NR) (Fig. 9b), it was observed that the adsorption efficiency and adsorption capacity were increased when the initial concentration of NR was increased in the range $(50-120 \mathrm{mg} / \mathrm{L})$. However, the adsorption capacity is improved when the initial dye concentration is important beyond $120 \mathrm{mg} / \mathrm{L}$ until $250 \mathrm{mg} / \mathrm{L}$ and the adsorption efficiency was unchanged. When initial dye concentration was increased beyond $250 \mathrm{mg} / \mathrm{L}$, the efficiency was decreased and the adsorption capacity $\left(q_{e}\right)$ was unchanged. This fact could be explained by the saturation of adsorption sites at the surface of clay.

The adsorption isotherm forms of NR dye are type $\mathrm{S}$ (not shown). The S-curve is generally result of cooperative adsorption with solute molecules tending to be adsorbed packed in rows or clusters. ${ }^{66}$ A type $\mathrm{S}$ isotherm appears when the binding energy of the first layer is lower than the binding energy between water molecules.

According to the obtained results (Fig. 8-b and Table 5), the best fit of experimental data for NR dye was obtained by the Dubinin-Radushkevich isotherm model (high $\mathrm{R}^{2}$ value compared to Langmuir and Freundlich isotherms models) with maximum adsorption capacities of $62.05 \mathrm{mg} / \mathrm{g}$ $(0.11 \mathrm{mmol} / \mathrm{g}), 170.11 \mathrm{mg} / \mathrm{g}(0.3 \mathrm{mmol} / \mathrm{g})$ and $201 \mathrm{mg} / \mathrm{g}(0.35 \mathrm{mmol} / \mathrm{g})$ for raw IMCM, Na-IMCM and FNa-IMCM, respectively.

Low adsorption affinity of anionic dye (NR) with inorganic clay materials compared to that of cationic dye (MB) is observed because (NR) dye molecule has the same negative charge as the clay surface. A physosorption assured by Vander Waals interactions is suggested.

Elmoubarki et al. ${ }^{67}$ are among many researchers that investigated the adsorption of textile dyes onto Moroccan clay materials. The experimental results show that, the adsorption capacity of cationic dyes (methylene blue MB and malachite green $\mathrm{MG}$ ) was found to be higher than anionic dye (methyl orange) and the adsorption isotherm could be well fitted by Langmuir equation in the case of cationic dyes and Dubinin-Radushkevich equation in the case of anionic dye. 
Table 4

Models isotherm constants for the MB dye adsorption onto inorganic clay materials

\begin{tabular}{c|c|c|c|c|c|c|c|c|c}
\hline & \multicolumn{3}{|c|}{ Langmuir } & \multicolumn{3}{c|}{ Freundlich } & \multicolumn{3}{c}{ Dubinin-Radushkevich } \\
\cline { 2 - 10 } & $\mathrm{q}_{\mathrm{m}}$ & $K$ & $R^{2}$ & $K_{f}$ & $n$ & $\mathrm{R}^{2}$ & $\begin{array}{c}\mathrm{q}_{\mathrm{m}} \\
(\mathrm{mg} / \mathrm{g})\end{array}$ & $\begin{array}{c}B .10^{-8} \\
(\mathrm{~mol} / \mathrm{j})\end{array}$ & $R^{2}$ \\
\hline Raw ICM & 315.45 & 0.35 & 0.997 & 201.83 & 10.98 & 0.800 & 401.30 & 1.71 & 0.749 \\
Na-ICM & 420.16 & 1.80 & 0.999 & 279.89 & 9.70 & 0.849 & 397.65 & 1.33 & 0.823 \\
FNa-ICM & 432.90 & 0.66 & 0.998 & 325.83 & 15.38 & 0.957 & 368.21 & 1.62 & 0.525 \\
\hline
\end{tabular}

Table 5

Models isotherm constants for the NR dye adsorption onto inorganic clay materials

\begin{tabular}{c|c|c|c|c|c|c|c|c|c}
\hline & \multicolumn{3}{|c|}{ Langmuir } & \multicolumn{3}{c|}{ Freundlich } & \multicolumn{3}{c}{ Dubinin-Radushkevich } \\
\cline { 2 - 9 } & $\mathrm{q}_{\mathrm{m}}(\mathrm{mg} / \mathrm{g})$ & $\mathrm{K}$ & $\mathrm{R}^{2}$ & $\mathrm{~K}_{\mathrm{f}}$ & $\mathrm{N}$ & $\mathrm{R}^{2}$ & $\begin{array}{c}\mathrm{q}_{\mathrm{m}} \\
(\mathrm{mg} / \mathrm{g})\end{array}$ & $\begin{array}{c}\mathrm{B} .10^{-} \\
4(\mathrm{~mol} / \mathrm{j})\end{array}$ & $\mathrm{R}^{2}$ \\
\hline Raw ICM & 116.41 & 0.0042 & 0.560 & 6.25 & 114.4 & 0.816 & 62.05 & 4.35 & 0.962 \\
Na-ICM & 806.45 & 0.0018 & 0.524 & 10.96 & 123.4 & 0.804 & 170.11 & 4.23 & 0.952 \\
FNa-ICM & 242.13 & 0.019 & 0.530 & 4.73 & 66.66 & 0.970 & 201.17 & 1.17 & 0.975 \\
\hline
\end{tabular}

\subsection{Dose of Adsorbent and Salinity Effects}

In Figure 11 was noticed that an increase in removal efficiency of the NR dye occurred when the adsorbent dosage was increased from 1 to 2 $\mathrm{g} / \mathrm{L}$. This increase in the removal efficiency of the dye is due to the formation of a large number of active adsorption sites as the amount of adsorbent increased. ${ }^{68}$

On the other hand, the decrease in the removal efficiency at doses more than $2 \mathrm{~g} / \mathrm{L}$ can be explained by the reduction of the active adsorption sites due to the partial aggregation of adsorbent particles at higher adsorbent doses. ${ }^{69}$

Ionic strength is an important parameter to be investigated in adsorption experiments because it is well known that industrial wastewaters always have pollutants such as inorganic salts. ${ }^{70}$ An increase in the ionic strength (for all used salts) of the medium increased the adsorbed amount of dye on the raw clay (Fig. 12).

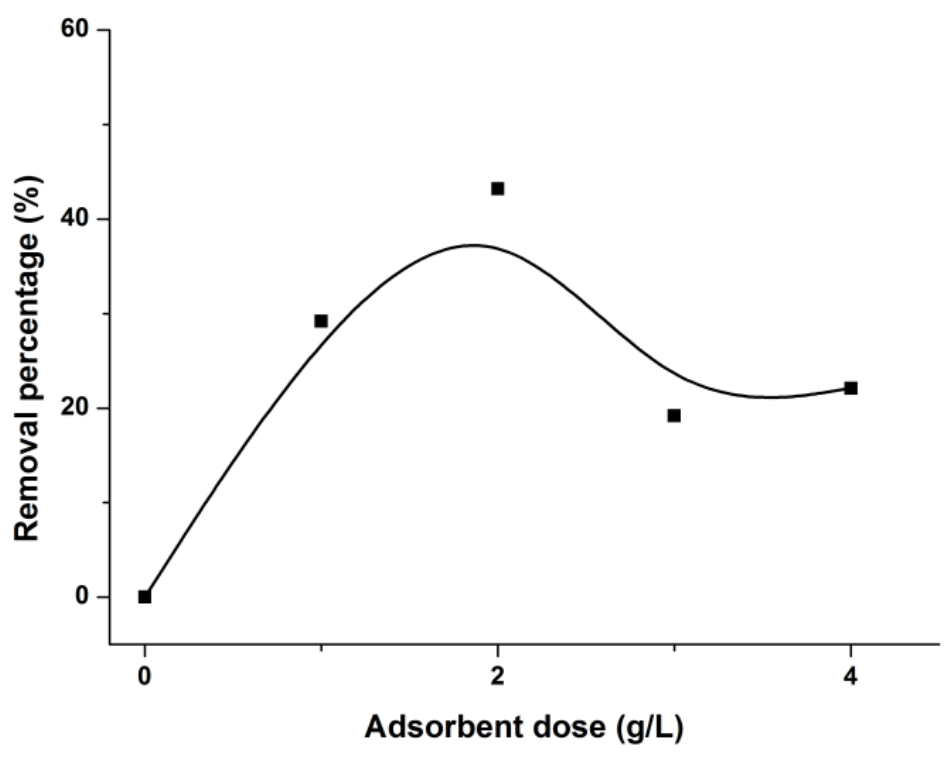

Fig. 11 - Effect of adsorbent (raw IMCM) dose on adsorption of NR dye. 


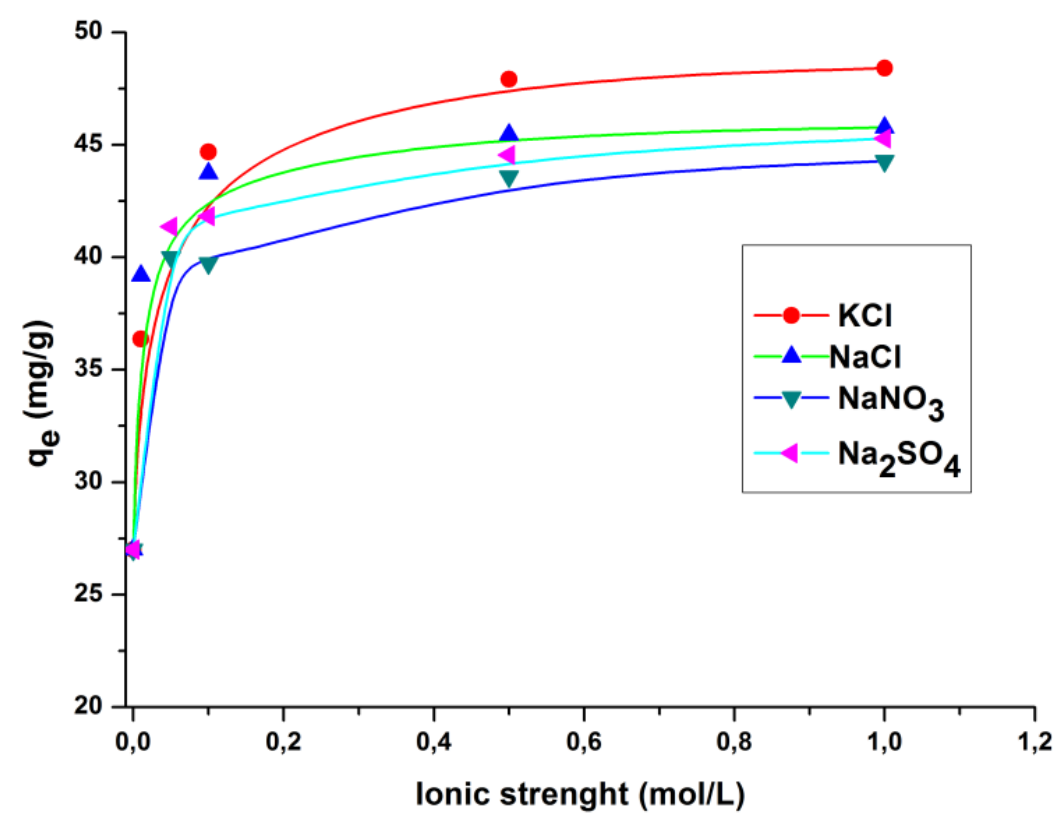

Fig. 12 - The effect of ionic strength to the adsorption uptake of NR on raw IMCM.

It is known that in a clay suspension, the particles are suspended in pure water and do not agglomerate, due to the interaction of the diffuse double layers. In the presence of an electrolyte (salt) the particles may approach each other so closely that they aggregate. The addition of the electrolyte led to an increase of the mean aggregate radius.

Luckham and Cione ${ }^{72,73}$ showed that a small addition of $\mathrm{Na}$ concentration led to the formation of edge-to-edge type aggregates, whereas a more concentrated solution resulted in the formation of very compact irregular aggregates having a multilayer structure of the face-to-face type. This results is supported by a study realised by ${ }^{74}$ to assess the removal of Congo Red, an acid dye using raw bentonite and surfactant-modified bentonite indicated that the adsorption of Congo Red, onto the negatively charged bentonite and positively charged of surfactant-modified bentonite was enhanced by adding the salts $(\mathrm{NaCl}, \mathrm{KCl}$, $\mathrm{CaCl}_{2}$ ).

\subsection{Comparison of Present Study with Previous Studies}

Various adsorbents for RN dye have been reported and listed in Table 6 for comparison with the inorganic clay materials (our study). The modified inorganic clay materials have adsorption capacities more than the adsorbents mentioned in the previous studies.

This study showed that the inorganic clay materials (raw IMCM, Na-IMCM and FNaIMCM) are able to retain high quantities of dye and can be used when highly polluted waters should be treated. In the next study, the FNaIMCM sample will also be modified using surfactant agent to investigate its adsorption capacity.

Table 6

The adsorption capacities of various reported adsorbents for Nylosan Red dye

\begin{tabular}{l|l|l}
\hline Adsorbents & $\mathrm{Q}_{\max }(\mathrm{mg} / \mathrm{g})$ & References \\
\hline Cynara cardunculus (CARD) and Eucalyptus globulus (EUCA) & 83.33 & {$[19]$} \\
& 83.33 & {$[19]$} \\
Prunus cerasifera (PRUN) & 76.92 & {$[19]$} \\
activated carbon (CGAC120) & 116 & {$[35]$} \\
HS & 25.18 & {$[75]$} \\
Raw inorganic clay material & 62 & This study \\
Sodic inorganic clay material (Na-IMCM) & 170 & This study \\
Fractionated sodic clay material (FNa-IMCM) & 201 & This study \\
\hline
\end{tabular}




\section{CONCLUSIONS}

This study shows that the inorganic montmorillonitic clay material (IMCM) in raw or modified forms (Na-IMCM and FNa-IMCM) can efficiently remove anionic textile dye (Nylosan Red) from aqueous solution. The adsorption was dependent on the $\mathrm{pH}$ of the aqueous solution, with a high uptake of NR dye at low pH. The adsorption was rapid and could be considered to fit pseudo-second order kinetics model. The equilibrium uptake was increased with increasing the initial concentration of dye in solution. The adsorption isotherm could be well fitted by Dubinin-Radushkevich model. The modification of raw montmorillonitic clay material improves its adsorption capacity. It is increased from $62.05 \mathrm{mg} / \mathrm{g}$ for raw material to 170.11 and $201.17 \mathrm{mg} / \mathrm{g}$ for sodic and fractionated sodic material, respectively. In the next study, another modification using a surfactant will be realized on FNa-IMCM sample to prepare the organic clay material to further improve its adsorption capacity.

\section{REFERENCES}

1. Shajahan, S. Shankar, A. Sathiyaseelan, S. K. Narayan, V. Narayanan, V. Kaviyarasan and S. Ignacimuthu, Int. J. Biol. Macromol., 2017, 104, 1449-1458.

2. J. Qiu, Y. Feng, X. Zhang, M. Jia and J. Yao, J.Colloid Interface Sci., 2017, 499, 151-158.

3. P. K. Malik and S. K. Saha, Sep. Purif. Technol., 2003, 31, 241-250.

4. J. Panswed and S. Wongchaisuwan, Water Sci. Technol., 1986, 18, 139-144.

5. F. Zhou, Y. Cheng, L. Gan, Z. Chen, M. Megharaj and R. Naidu, Ecotox. Environ. Saf., 2014, 105, 1-6.

6. D. K. Gardiner and B. J. Borne, J. Soc. Dyers Colour., 1978, 94, 339-348.

7. G. Ciardelli, L. Corsi and M. Marucci, Resour. Conserv. Recycl., 2000, 31, 189-197.

8. K. B. Tan, M. Vakili, B. A. Horri, P. E. Poh and A. Z. Abdullah, Sep. Purif. Technol., 2015, 150, 229-242.

9. S. Ledakowicz, M. Solecka and R. Zylla, J. Biotechnol., 2001, 89, 175-184.

10. Z. Chen, T. Wang, X. Jin, Z. Chen, M. Megharaj and R. Naidu, J.Colloid Interface Sci., 2013, 398, 59-66.

11. N. Guo, J. S. Wang, J. Li, Y. G. Teng and Y. Z. Zhai, Clays Clay Miner., 2014, 62, 415-424.

12. S. Dawood and T. Kanti Sen, Water Res., 2012, 46, 19331946.

13. M. A. Ahmad and R. Alrozi, Chem. Eng. J., 2011, 171, 510-516.

14. T. Depci, A. R. Kul and Y. Önal, Chem. Eng. J., 2012, 200-202, 224-236.

15. G. O. El-Sayed, Desalination., 2011, 272, 225-232.

16. F. Bouaziz, M. Koubaa, F. Kallel, R. E. Ghorbel and S. E. Chaabouni, Int. J. Biol. Macromol., 2017, 105, 56-65.

17. N. Barka, A. Assabbane, A. Nounah, L. Laanab and Y. AîtIchou, Desalination., 2009, 23, 5264-5275.
18. N. Barka, K. Ouzaouit, M. Abdennouri and M. ElMakhfouk, J. Taiwan Inst.Chem.Eng., 2013, 44, 52-60.

19. Ouldmoumna, N. Benderdouche, L. Reinert, B. Benaouda and L. Duclaux. Desalin. Water Treat., 2017, 65, 304312.

20. H. Hosseinzadeh and K. Abdi, J. Inorg. Organomet. Polym. Mat., 2017, 27, 1595-1612.

21. S. Kaushal, R. Badru, S. Kumar, H. Kaur and P. Singh, J. Inorg. Organomet. Polym. Mat., 2018, 28, 968-977.

22. Z. Yang, K. Fu, J. Yu and X. Liu, J. Inorg. Organomet. Polym. Mat., 2019, 29, 59-65.

23. H. Hosseinzadeh and K. Abdi, J. Inorg. Organomet. Polym. Mat., 2017, 27, 1595-1612.

24. P. Sharma, D. J. Borah, P. Das and M. R. Das, Desalin. Water Treat., 2015, 57, 8372-8388.

25. O. Sözüdoğru, B. A. Fil, R. Boncukcuoğlu, E. Aladağ and S. Kul, Particul. Sci. Technol., 2015, 34, 103-111.

26. D. Ozdes, C. Duran, H.B. Senturk, H. Avan and B. Bicer, Desalin. Water Treat., 2014, 52, 208-218.

27. W. T. Tsai, C. Y. Chang, C. H. Ing and C. F. Chang, J. Colloid Interface Sci., 2004 27, 572-578.

28. M. Chaari, Medhioub and F. Jamoussi, J. Appl. Sci. Environ. Sanitat., 2011, 6, 143-148.

29. G. Lagaly, "Colloid clay science", in F. Bergaya, B. K. G. Theng and G. Lagaly (Eds.), "Handbook of Clay Science. Developments in Clay Science 1. Science", Amsterdam: Elsevier publishing, 2006, p. 141-245.

30. M. Duc, F. Thomas and F. Gaboriaud, J. Colloid Interf. Sci., 2006, 300, 616-625.

31. E. Tombacz and M. Szekeres, Appl. Clay Sci., 2006, 34, 105-124.

32. E. Errais, J. Duplay, F. Darragi, I. M'Rabet, A. Aubert, F. Huber and G. Morvan, Desalination., 2011, 275, 74-81.

33. M. Khemila, B. Merzouk, A. Chouder, R. Zidelkhir, J-P. Leclerc and F. Lapicque, Sustainable Chem. Pharmacy., 2018, 7, 27-35.

34. Belayachi-Haddad, N. Benderdouche, B. Benaouda and L. Duclaux, Desalin. Water Treat., 2017, 63, 78-86.

35. Reffas, V. Bernardet, B. David, L. Reinert, M. Bencheikh Lehocine, M. Dubois, N. Batisse and L. Duclaux, J. Hazardous Materials., 2010, 175, 779-788.

36. N. Ladjal, B. Zidelkheir and S. Terchi, J. Therm. Anal. Calorim., 2018, 134, 881-888.

37. N. Yener, C. Bicer, M. Onal and Y. Sarıkaya, Appl. Surface Sci., 2012, 258, 2534-2539.

38. Y. Yukselen and A. Kaya, Eng. Geol., 2008, 102, 38-45.

39. C. Santamarina, K. A. Klein, Y. H. Wang and E. Prencke, Can. Geotech. J., 2002, 39, 233-241.

40. P. T. Hang, G. W. Brindley, Clays Clay Miner., 1970, 18, 203-212.

41. G. Chen, J. Pan, B. Han and H. Yan, J. Disper. Sci. Technol., 1999, 20, 1179-1187.

42. S. Sahnoun, M. Boutahala, C. Tiar and A. Kahoul, Comptes Rendus Chimie., 2018, 21, 391-398.

43. Tabtiang, S. Lumlong and R. A. Venables, Eur Polym J., 2000, 36, 2559-2568.

44. Z. P. Tomic, D. P. Asanin, R. Durovic-Pejcev, A. Dordevic and P. Makreski, Spectrosc Lett., 2015, 48, 685-690.

45. Elkhalifah, S. Maitra, M. A. Bustam and T. Murugesan, J. Therm Anal Calorim., 2012, 110, 765-771.

46. Y. Xi, W. Martens, H. He and R. L. Frost, J. Therm. Anal. Calorim., 2005, 81, 91-97.

47. Q. Zhou, R. L Frost, H. He and Y. Xi, J Colloid Interface Sci., 2007, 307, 50-55. 
48. Bouguettoucha, A. Reffas, D. Chebli and A. Amrane, Iran. J. Chem. Chem. Eng., 2017, 36, 87-96.

49. H. Kausar, M. Iqbal, A. Javed, K. Aftab, Z. H. Nazli, H. N. Bhatti and S. Nouren, J. Molecular Liquids., 2018, 256, 395-407.

50. H. Soltani, A. Belmokhtar, F. Z. Zeggai, A. Benyoucef, S. Bousalem and K. Bachari, J. Inorg. Organomet. Polym. Mat., 2019, 29, 841-850.

51. Z. X. Han, Z. Zhu, D. D. Wu, J. Wu and Y. R. Liu, Synth. React. Inorg. Met., 2014, 44, 140-147.

52. F. Tümsek and O. Avci, J. Chem. Eng. Data., 2013, 58, 551-559.

53. R. Chinoune, K. Bentale, Z. Bouberka, A. Nadim and U. Maschke, Appl. Clay Sci., 2016, 123, 64-75.

54. S. C. R. Santos, A. F. M. Oliveira and R. A. R. Boaventura, J. Clean. Prod., 2016, 126, 667-676

55. M. Fayazi, D. Afzali, M.A. Taher, A. Mostafavi and V. K. Gupta, J. Mol. Liq., 2015, 212, 675-685

56. S. Lagergren, About the theory of so-called adsorption of soluble substances, K. Sven. Vetensk. Akad. Handl., 1898, $24,1-39$.

57. K.G. Bhatacharyya and A. Sharma, J. Environ. Manag., 2004, 71, 217-229.

58. R. Gundogan, B. Acemioglu and M. Alma, J. Colloid Interface Sci., 2004, 269, 303-309.

59. J. Yue, Y. Jing, J. Ma, C. Xia and Y. X. Y. Jia, Desalination., 2011, 267, 9-15.

60. Langmuir, J. Am. Chem. Soc., 1916, 38, 2221-2295.

61. H. Freundlich and W. Heller, J. Am. Chem. Soc., 1939, $61,2228-2230$.
62. M. Dubinin and L. V. Radushkevich, Proc. Acad. Sci. USSR Phys. Chem. Sec., 1947, 55, 331-337.

63. T. S. Anirudhan and M. Ramachandran, Process Saf. Environ. Prot., 2015, 95, 215-225.

64. X. Yu, C. Wei and H. Wu, Sep. Purif. Technol., 2015, 156, 489-495.

65. H. Giles, T. H. Mac Evan, S. N. Nakhwa and D. Smith, J. Chem. Soc., 1960, 1, 113973-113993.

66. H. Giles, A. P. D'Silva and I. A. Easton, J. Colloid Interface Sci., 1974, 47, 766-778.

67. R. Elmoubarki, F. Z. Mahjoubi, H. Tounsadi, J. Moustadraf, M. Abdennouri, A. Zouhri, A. El Albani and N. Barka, Water Resources and Industry., 2015, 9, 16-29.

68. H. Bensalah, M. F. Bekheet, S. A. Younssi, M. Ouammou and A. Gurlo. J Environ. Chem. Eng., 2017, 5, 2189-2199.

69. J. S. Wang, R. T. Peng, J. H. Yang, Y. C. Liu and X. J. $\mathrm{Hu}$, Carbohyd. Polym., 2011, 84, 1169-1175.

70. T. Ngulube, J. R. Gumbo, V. Masindi and A. Maity, J. Environ. Management., 2017, 191, 35-57.

71. J. Errais, J. Duplay, F. Darragi, I. M'Rabet, A. Aubert, F. Huber and G. Morvan, Desalination., 2011, 275, 74-81.

72. P. F. Luckham and S. Rossi, J. Colloid Interface Sci., 1999, 82, 43-92.

73. P. P. Cione, C. C. Schmitt, M. G. Neumann and F. Gessner, J. Colloid Interface Sci., 2000, 226, 205-209.

74. A. Ma, A. M. Youssef and M. M. Al-Awadhi, J. Anal. Bioanal. Tech., 2013, 4, 174-180.

75. S. Karakus, N. Tasaltın, C. Tasaltın and A. Kilislioglu, Surf. Interfaces, 2020, 20, 100528. 